\title{
A Newly Recognized Autosomal Dominant Limb Girdle Muscular Dystrophy with Cardiac Involvement
}

\author{
A. J. van der Kooi, MD,* T. M. Ledderhof,* W. G. de Voogt, MD, $\dagger$. C. J. Res, MD, $\ddagger$ G. Bouwsma, MD, ${ }^{*}$ \\ D. Troost, MD, $\$$ H. F. M. Busch, MD,\|A. E. Becker, MD, 9 and M. de Visser, MD*
}

Sixty-five members of three families with limb girdle muscular dystrophy (LGMD) underwent neurological, cardiological, and ancillary investigations. Thirty-five individuals were diagnosed as having slowly progressive autosomal dominant LGMD. Symmetrical weakness started in the proximal lower limb muscles, and gradually upper limb muscles also became affected. Early contractures of the spine were absent. Contractures of elbows and Achilles tendons were either minimal or late. Serum creatine kinase activity was normal to moderately elevated. Electromyogram and muscle biopsy were consistent with a mild muscular dystrophy. Cardiological abnormalities, found in more than one-half the patients, included dysrhythmias and atrioventricular (AV) conduction disturbances presenting as bradycardia, syncopal attacks necessitating pacemaker implantation, and sudden cardiac death. There was a significant relation between the severity of AV conduction disturbances and age. In nearly all patients, neuromuscular symptomatology preceded cardiological involvement. The early recognition of this previously not described, autosomal dominant LGMD with life-threatening cardiac involvement offers an opportunity for therapeutic intervention.

van der Kooi AJ, Ledderhof TM, de Voogt WG, Res JCJ, Bouwsma G, Troost D, Busch HFM, Becker AE, de Visser M. A newly recognized autosomal dominant limb girdle muscular dystrophy with cardiac involvement. Ann Neurol 1996;39:636-642

Cardiac involvement is well documented in various forms of muscular dystrophy, such as Duchenne, Becker, Emery-Dreifuss, and myotonic dystrophy. Its prevalence, severity, and distinctive characteristics vary from one type of dystrophy to another [1-9]. Limb girdle muscular dystrophy (LGMD) constitutes a heterogeneous group of disorders with a limb girdle distribution of weakness. During a recent workshop, criteria for inclusion and exclusion of the diagnosis have been suggested [10]. Although cardiological involvement has been described in LGMD $[1,3,6,11-13]$, in more recent reports, clinically overt cardiac abnormalities appear to be rare $[4,14,15]$.

In this report, we describe three families with a unique neuromuscular disease of myopathic origin, characterized by autosomal dominant inheritance, slowly progressive limb girdle weakness, the absence of early contractures, and cardiopathy with life-threatening arrhythmias.

\section{Subjects and Methods}

Subjects

Sixty-five members of three families (27 individuals from family A, 35 from family B, and 3 from family C), of which one origi- nated from The Netherlands (A), one from Surinam (B), and one from the Caribbean $(C)$, underwent neurological, cardiological, and biological investigations after having given their informed consent. Pedigrees are shown in Figure 1. Asymptomatic persons under the age of 18 were excluded from the study. In 11 deceased subjects ( 4 in family A, 6 in family $B$, and 1 in family C) and 9 subjects living abroad ( 7 in family B, 2 in family C), the history was given by the family.

\section{Neurological Investigations}

The patients and family members were examined by using a standardized protocol to determine age and symptoms at onset, disease duration, and clinical features, including pulmonary function tests. Some were investigated at home, but the majority was examined in our hospital.

The three index cases (AII-9, BIII-8, CII-6) met the diagnostic criteria for limb girdle dystrophy [10], i.e., slowly progressive symmetrical proximal weakness with onset in the lower limbs, gradual involvement of the upper limbs, normal to mildly raised serum creatine kinase (CK) activity, myopathic changes on electromyography (EMG) and muscle biopsy, and normal dystrophin analysis of the muscle tissue.

For other individuals within these families, the presence of proximal weakness in at least the lower limbs, or CK
From the Departments of *Neurology, $\neq$ Cardiology, $\$$ Neuropathology, and ICardiovascular Pathology, Academical Medical Center, and tDepartment of Cardiology, Hospital St Lucas, Amsterdam; and IDepartment of Neurology, Acadernical Hospital Dijkzigt, Rotterdam, The Netherlands.
Received Aug 15, 1995, and in revised form Dec 4. Accepted for publication Dec 6, 1995.

Address correspondence to Dr van der Kooi, Department of Neurology, Academic Medical Center, University of Amsterdam, PO Box 22700, 1100 DE Amsterdam, The Netherlands. 

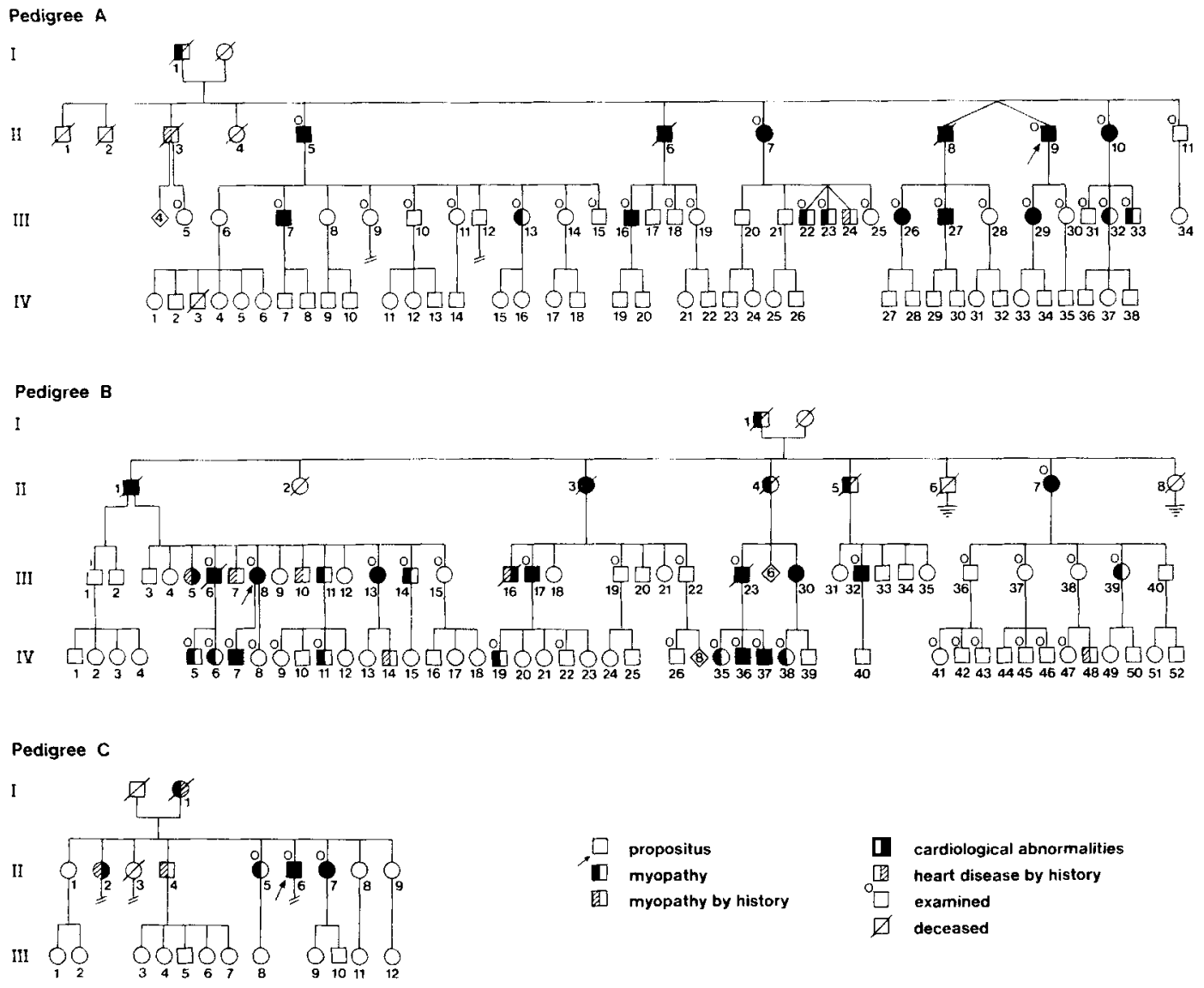

Fig 1. Pedigrees of families $A, B$, and $C$.

elevation (greater than two times the normal value) was required for inclusion in the affected group.

\section{Cardiological Investigations}

This included history, physical examination, 12-lead scalar electrocardiogram (ECG), two-dimensional and $\mathrm{M}$-mode echocardiography, and color flow Doppler in 51 subjects (23 of family A, 27 of family B, 1 of family C). In 29 persons, 24-hour ECG monitoring, and in 3, cardiac muscle biopsy, were performed. From 16 other subjects, including some of the deceased, cardiologic information was obtained from their cardiologists. Abnormalities were classified as arrhythmias, either bradycardias or tachycardias, and echocardiographic wall-motion abnormalities indicating a myocardial muscle disease. Other findings such as coronary artery disease were classified as miscellaneous.

\section{Biological Investigations}

In 65 members of the three families, serum CK activity was assessed. EMG, including nerve-conduction studies, was performed in 5 members of family $A$ and 2 individuals of family B. Biopsy specimens of the biceps brachii or quadriceps muscle were obtained from 10 subjects ( 3 of family A, 4 of family $\mathrm{B}$, and 3 of family C) for histopathological and histochemical studies.
Postmortem examination was performed in 2 individuals (AII-6, BIII-6) who had died suddenly.

$\chi^{2}$ tests were conducted to analyze the relationship between the severity of atrioventricular (AV) conduction disturbances and age.

\section{Results}

Neurological Evaluation

Among the 65 examined subjects, 35 (14 in family A, 18 in family $B$, and 3 in family $C$; 15 females, 20 males, ranging in age from 15 to 66 years) were diagnosed as having LGMD. Thirty-four individuals had neuromuscular symptoms, and one 27-year-old male was clinically asymptomatic but had an elevated serum CK activity (25 times the normal value). Eleven deceased subjects and 9 individuals living abroad were presumed to be affected according to the history given by the family.

The pattern of inheritance of the muscle disorder in families $A$ and $B$ is autosomal dominant. Affected persons were found in at least three generations, males and females were equally affected, and male-to-male transmission was present. In family $\mathrm{C}$, transmission is 
Table 1. Clinical Data and Results of Ancillary Investigations in Three Families with Autosomal Dominant Limb Girdle Muscular Dystrophy

\begin{tabular}{|c|c|c|c|c|c|c|c|c|c|}
\hline Family & $\begin{array}{l}\text { No. of } \\
\text { Individuals } \\
\text { Examined }\end{array}$ & $\begin{array}{l}\text { Age } \\
(\mathrm{yr})\end{array}$ & $\begin{array}{l}\text { No. of } \\
\text { Individuals } \\
\text { Affected }\end{array}$ & $\begin{array}{l}\text { Age of } \\
\text { Onset }(y r)\end{array}$ & $\begin{array}{l}\text { Weakness } \\
\text { at Onset }\end{array}$ & Progression & $\begin{array}{l}\text { CK ( } \times \text { Normal } \\
\text { Value })\end{array}$ & EMG & $\begin{array}{l}\text { Muscle } \\
\text { Biopsy }\end{array}$ \\
\hline A & 27 & $20-66$ & 14 & $5-38$ & PLL & Mild & $N-4$ & M & M \\
\hline B & 35 & $15-65$ & 18 & $4-29$ & PLL & Mild & $\mathrm{N}-25$ & $\mathrm{M}$ & M \\
\hline $\mathrm{C}$ & 3 & $36-39$ & 3 & $4-19$ & PLL & Mild & $6-13$ & M & M \\
\hline
\end{tabular}

$\mathrm{CK}=$ creatine kinase $\mathrm{EMG}=$ electromyogram; $\mathrm{N}=$ normal; $\mathrm{M}=$ myopathic; $\mathrm{PLL}=$ proximal lower limbs.

suggestive of autosomal dominant inheritance, because of the presence of affected persons in two generations.

The neurological data and results of ancillary investigations are presented in Table 1. All patients had normal motor milestones. Age of onset varied from 4 to 38 years. In one-half the patients the onset was in childhood with a typical waddling gait, an abnormal posture with hyperlordosis, or difficulty with running. Subsequently, there was difficulty in climbing stairs and in arising from a squatting position. Muscle weakness was slowly progressive, causing moderate impairment in the sixth or seventh decade. The first abnormalities found on examination were an increased lumbar lordosis, a positive Gowers' sign, and hip girdle or proximal leg weakness. Mild symmetrical weakness and wasting of proximal arm muscles, affecting predominantly the biceps brachii muscle, occurred around the age of 40 . Restriction of neck or spine flexion was absent. Flexion contractures of elbows and Achilles tendons were either minimal or late, although 2 individuals (AIII-26, BIII-32) underwent Achilles tenotomy in their teens. Mild symmetrical facial involvement was seen in 3 individuals. Some distal leg involvement was observed in 8 individuals, but proximal weakness was always more severe. Calf hypertrophy was seen in 6 individuals. Sensation was not impaired. Deep tendon reflexes were reduced or absent. Myotonia was not present. Pulmonary function was either normal or slightly reduced.

Serum CK activity was normal in 7 and elevated (median, three times the normal value) in 28 affected individuals.

Motor and sensory nerve conduction velociries were normal in all patients investigated. Needle examination showed polyphasic short-duration, low-amplitude motor unit action potentials, with fast recruitment in predominantly the proximal muscles, but to a lesser extent also in distal muscles.

Muscle biospy showed predominantly nonspecific myopathic changes in both fiber types, such as fiber size variation, increase in the number of fibers with internal nuclei, fiber splitting, and slight endomysial frbrosis and fatty infiltration (Fig 2). In seven biopsies (AII-6, 9, AIII-29, BIII-6, CII-5, 6, 7) an occasional

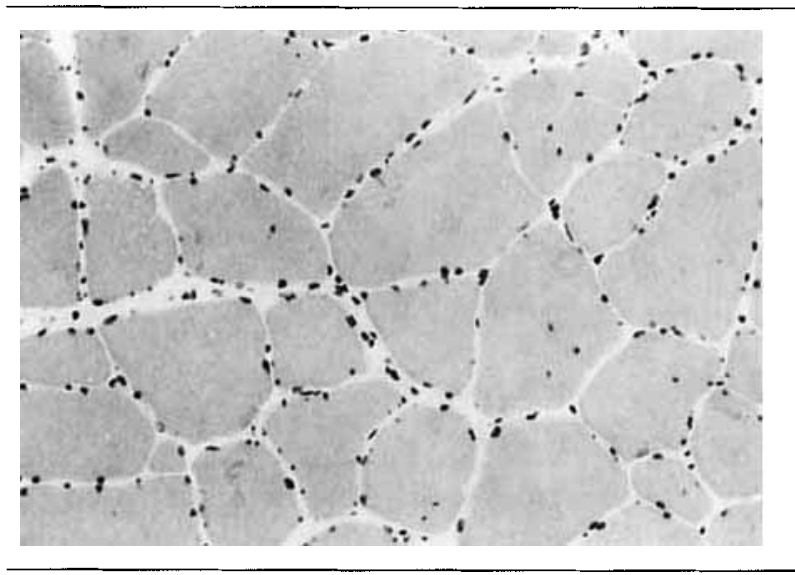

Fig 2. Biopsy specimen from the biceps brachii muscle showing myopathic changes, including muscle-fiber size variation, an increase in the number of fibers with internal nuclei, and fiber splitting (hematoxylin and eosin stain) ( $\times 50$ before $36 \%$ reduction).

necrotic fiber with phagocytosis or regenerating fiber was seen. Other structural changes included motheaten fibers (AII-9) and rimmed vacuoles (3\%) (BIII-8). Electron microscopy in the latter showed filamentous inclusions. A few atrophic angulated fibers were found in nearly all muscle biopsy specimens, but in only two specimens these fibers reacted stongly with oxidative enzymes. Immunohistochemical and immunobiochemical dystrophin analysis in the muscle biopsy specimens of the 3 index cases was normal.

Postmortem examination of the spinal cord of AII-6 showed normal motor neurons.

\section{Cardiological Evaluation}

Information about cardiological investigations was available in 67 subjects (51 personally examined; for 16 individuals data from their own cardiologists were obtained). Sudden cardiac death, witnessed by relatives, occurred in 8 patients (AII-3, 6, 8, BI-1, BII-5, BIII-6, 16, CI-1) at a relatively young age (median, 50 years; range, $42-76$ years). In Table 2 , the characteristics of $\mathrm{AV}$ conduction in 40 individuals with neuromuscular 
Table 2. Characteristics of Atrioventricular Conduction in 40 Individuals with Neuromuscular Symptoms ${ }^{2}$

\begin{tabular}{lccccc}
\hline Age (yr) & $15-25$ & $25-35$ & $35-45$ & $45-55$ & $55-65$ \\
Normal & 5 & 10 & - & - & - \\
First-degree AV block & - & 4 & 1 & - & - \\
Second-degree AV block & - & 1 & 2 & - & - \\
High-degree and total AV block & - & - & 4 & 2 & 7 \\
Pacemaker implantation & - & - & 1 & 1 \\
\hline
\end{tabular}

${ }^{a}$ Thirty-five patients were clinically examined; from an additional 5 patients, cardiological information was available.

$\mathrm{AV}=$ atrioventricular.

symptoms are shown. Five subjects showed first-degree AV block. In 3 individuals, second-degree AV block was present, 2 showing Wenckebach type and 1 a 2:1 AV conduction. In 6 individuals, atrial fibrillation with slow ventricular response rates (frequency, 28-50/min) was found. In the absence of medication influencing AV conduction, this is indicative of intrinsic AV block. AIII16 also had a total AV block with slow ventricular response rates. A pacemaker had been implanted in 10 individuals (AII-5, 6, 8, 10, BII-1, 3, 7, BIII-17, 30, CII-6) because of symptomatic high-degree or total AV block (Fig 3). Fourteen of the 51 examined patients complained of palpitations. One patient had paroxysmal atrial fibrillation with fast ventricle response. Frequent supraventricular premature beats were recorded in 11 individuals on Holter electrocardiography. Short ventricular tachycardias, runs from 2 to 6 beats, were seen in 11 patients. In another 4 patients (BII-7, BIII-8, 17, 23), signs of sick sinus syndrome were found, such as sinus bradycardia and sinus arrest.

Dilated cardiomyopathy was documented with echocardiography in 2 patients (AIII-7, BIII-16). AIII-7 presented at the age of 39 with acute heart failure. BIII-16 presented at the age of 46 with fatigue and nausea that had been present for a week. He had atrial fibrillation with slow response rates and a dilated cardiomyopathy. $\mathrm{He}$ died suddenly at the age of 47 . Postmortem examination was not executed. Echocardiography showed wall-motion disturbances of the intraventricular septum in 2 individuals (AII-9, BIII-23), of whom 1 had a left bundle branch block. Left atrial enlargement was observed in 6 patients (AII-9, BII-7, BIII-6, 16, 17, CII-7), all with atrial rhythm disturbances.

Patient AII-6 died suddenly at the age of 63 years. He was known to have had heart disease and had had a pacemaker implanted. The postmortem examination revealed cardiomegaly with dilation of all cardiac chambers. The left ventricular myocardium showed extensive replacement fibrosis, which extended also into the ventricular septum. The septal AV junction area was markedly attenuated as part of the chamber dilation. The AV node was in its normal position. At the site of the anticipated penetrating (His) bundle, however, the larger part of the specialized conduction cells was replaced by fibrous tissue. The crest of the ventricular septum, moreover, contained extensive replacement fibrosis. The pathologic findings suggest an acquired degenerative process related to molding of the central fibrous body as a consequence of massive dilation of heart chambers.

Another patient, BIII-6, died suddenly at the age of 47, and he was known to have atrial fibrillation with slow response rates and ventricular premature beats. Postmortem investigation and cardiac angiography

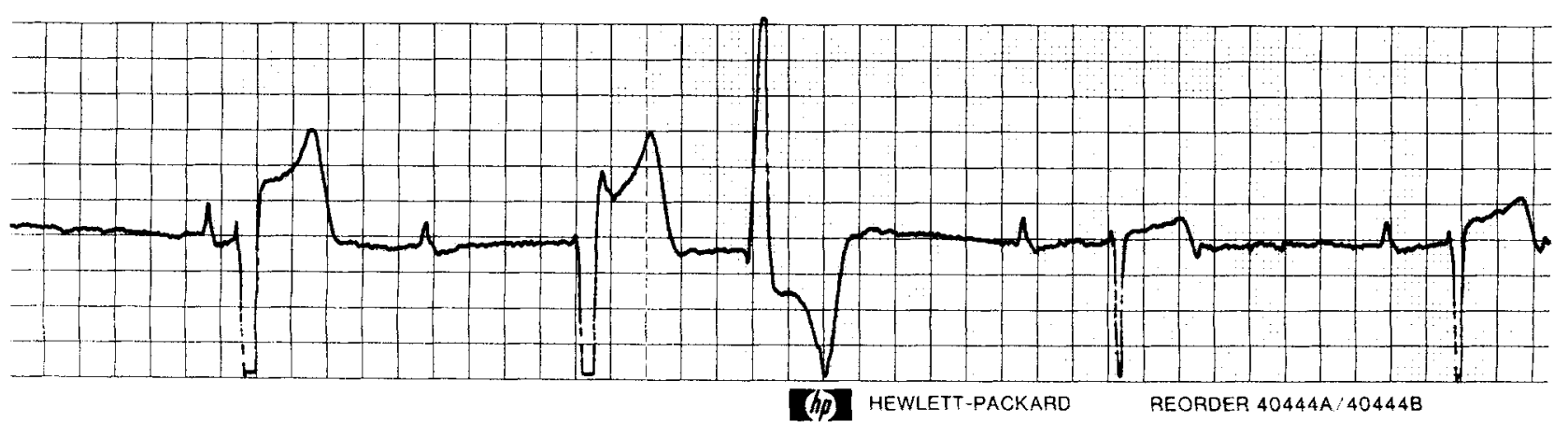

Fig 3. Rhythm strip of AII-10, after electroconversion from atrial flbrillation to sinus rhythm, showing total atrioventricular block with junctional escape rhythm, and a ventricular extrasystole (paper speed $=25 \mathrm{~mm} / \mathrm{sec}$ ). 
showed a hypertrophic heart with a moderate stenosis of the right coronary artery. No ischemic changes could be demonstrated in the cardiac muscle cells. The conduction system was not analyzed.

Cardiac muscle biopsy in 3 cases (AIII-7, BIII-16, CII-7) showed nonspecific fibrotic changes.

A history of ischemic heart disease was given by 8 of the 40 LGMD patients (AII-5, 6, 7, 8, 9, BIII-17, 23,32 ), and by 2 of the unaffected family members (AII-11, BIII-19) in whom cardiological information was available. Three (AII-5, 6, 11) underwent coronary artery bypass grafting, and the other 7 had myocardial infarction. One of them (BIII-32) had severe pump failure on the basis of ischemic heart disease and was presented for cardiac transplantation.

One patient (BIII-37) suffered from systemic lupus erythematosus (SLE) and showed pericarditis.

\section{Relation Between Cardiological and Neurological Observations}

Cardiological abnormalities were found in 21 of the 35 examined patients with LGMD (and in an additional 4 of the 5 patients with LGMD in whom cardiological information was available) (see Fig 1, Table 2) and consisted of conduction disorders, presenting as first-, second-, or third-degree AV block, and atrial fibrillation with high-degree AV block. Myocardial muscle disease resulting in congestive cardiomyopathy was found in 2 individuals. No medical records documenting sudden cardiac death were available. Possible causes may be either severe bradyarrhythmias or tachyarrhythmias, such as ventricular tachycardia or fibrillation, or coronary artery disease.

With the exception of 2 patients, the AV conduction disturbances were never present without and always preceded by neuromuscular symptoms. The cardiac symptoms could be the most prominent. One patient (BIII-16) even died of cardiac disease, without LGMD having been diagnosed. In retrospect, he was said to have had the neuromuscular symptoms characteristic of the disorder. Another 27-year-old individual (BIV37) showed alternating first- and second-degree AV block on his ECG but no muscle weakness. Calf hypertrophy and a markedly raised serum CK activity (up to 25 times the normal value) indicated (presymptomatic) neuromuscular disease. $\chi^{2}$ testing showed a significant relation between the severity of AV conduction disturbances and age $(p<0.001)$.

\section{Discussion}

We identified 35 individuals within three families with an autosomal dominantly inherited progressive limb girdle muscular weakness. The presenting symptoms were due to hip girdle or proximal leg weakness and occurred predominantly in the first two decades. Weakness of the shoulder girdle, upper arm muscles, and distal leg muscles occurred at a later stage of the disease, and slight symmetrical facial weakness was seen in only 3 patients. Eleven patients showed either minimal or late contractures of elbows and Achilles tendons. Progression of the neuromuscular disease was mild, since no patient became wheelchair dependent. There was marked inter- and intrafamilial variability. Serum CK activity was normal to mildly elevated in most of the patients. On the basis of electrophysiologi$\mathrm{cal}$ and histopathological investigations, it can be concluded that we are dealing with a mild muscular dystrophy. All these features found in our families can fit in a general description of autosomal dominant LGMD, but the cardiological involvement, present in more than one-half our patients, is exceptional.

Recently, two forms of LGMD with autosomal dominant inheritance were distinguished $[16,17]$. One form, called Bethlem myopathy [18], has an early, often congenital onset and is characterized by proximal or generalized muscle weakness, joint contractures, and absence of cardiac signs and symptoms [5]. The other form constitutes a heterogeneous group of disorders with later onset and a slowly progressive course [1928]. No cardiac involvement was noted, except for the family described by De Coster and associates [21], who found mild repolarization disturbances on ECG in 1 individual. The main cardiologic manifestations in our families comprised conduction disturbances in the atrial region, AV node, and bundle of His, presenting as AV block, atrial fibrillation with high-degree AV block and junctional escape rhythm, bradycardia especially during the night, and syncopal attacks. The 1 patient in whom the cardiac AV conduction system could be studied showed extensive degenerative disease that involved the His bundle at the site of penetration into the central fibrous body. The area was markedly attenuated, which correlated with distinct dilation of the cardiac chambers. These changes, moreover, also tended to affect the AV conduction. This could provide the anatomic substrate for AV nodal dissociation and total AV block. In addition, it may anticipate from these findings that with increasing age, the AV conduction disturbances will become more severe. Indeed, the statistically significant higher frequency of severe cardiological disturbances in the older age groups endorses this conclusion. To what extent replacement fibrosis of myocardium as part of ischemic heart disease plays an additional role remains speculative. Since ischemic heart disease was found both in individuals with and without LGMD, it is not believed to be the underlying cause of the conduction disturbances that were found in concomitant presence with the neuromuscular disease. Since the latter is the case, cardiological screening by ECG and 24-h ECG of family members presenting with neuromuscular signs and symptoms is recommended. Follow-up is mandatory when abnormalities are found, and implantation of a pacemaker to prevent sudden cardiac death should be considered 
when extreme bradycardias and related symptoms are present. Fortuitous ventricular arrhythmias, however, are more difficult to be influenced.

In only 2 patients a congestive cardiomyopathy was encountered. Thus, in our families it seems unlikely that the conduction disturbances and cardiomyopathy are to be considered mutually dependent as suggested by some authors [29]. The presence of congestive heart failure seems an additional risk factor for sudden death. Lifethreatening conduction disturbances are described in only a few neuromuscular disorders, including myotonic dystrophy and a genetically heterogeneous variant [4, 30, 31], a multisystem disorder, and Emery-Dreifuss muscular dystrophy (EDMD) $[7,8]$. The latter is characterized by early contractures of the Achilles tendons, elbows, and postcervical muscles, slowly progressive wasting and weakness with a predominantly humeroperoneal distribution, and cardiomyopathy with conduction defects $[7,8,32]$. Predominantly myopathic changes on EMG and muscle biopsy have been described, although some authors [33, 34] also found neurogenic changes. Most families show X-linked recessive inheritance. The gene responsible for EDMD was recently identified in the telomeric moiety of $\mathrm{Xq} 28$. Various mutations were found in the STA gene causing lack of the protein emerin [35-38]. There have been several reports of families with (possible) autosomal dominant scapulo-humero-peroneal weakness with cardiopathy [39-51], which according to Emery [52] should be considered EDMD. As yet, the gene(s) responsible for this phenotypically identical disease is not identified.

In contrast to EDMD, the affected individuals in our families presented with slowly progressive pelvic girdle weakness with only late involvement of the humeral muscles and sparing of the peroneal and tibial muscles. In 6 of our patients, calf enlargement was seen, which has been an exclusion criterion for EDMD [32]. Early contractures of neck, spine, elbows, and Achilles tendons, being a salient feature of EDMD, were absent in our patients. In nearly all the affected individuals of our families, neuromuscular symptoms precede the cardiological disturbances, whereas in EDMD cardiological involvement may occur at any age or may even be present at the very onset $[7,8,32]$.

There are a few anecdotal reports of families with evidence of possible autosomal dominantly or recessively inherited humeropelvic weakness and cardiac involvement [53-55]. Because of contractures occurring in childhood, these families are also regarded as having EDMD [52].

The neurological manifestations in the family described by Graham [56] resemble those encountered in our families in some respects, but the cardiological manifestations consisting of predominant left ventricle hypertrophy are clearly different.

Rimmed vacuoles and filamentous inclusions were encountered in only one of the 10 biopsy specimens of our patients. Therefore, a diagnosis of familial inclusion body myositis, or autosomal dominant LGMD with rimmed vacuoles, as described by Chutkow and colleagues [20], is considered unlikely. Probably, we are dealing with a nonspecific feature [57].

Therefore, we conclude that the patients in our families are suffering from a new, hitherto not described, disease entity in which cardiac involvement predominates the clinical picture. Timely recognition of this disorder may offer an opportunity for therapeutic cardiological intervention.

We are particularly grateful to the Prinses Beatrix Fonds for financial support, the patients for their cooperation, J. H. Th. M. Koelman, MD, for performing the electromyographical studies, R. J. de Haan, PhD, for help with statistical analysis, and W. C. G. Overweg-Plandsoen, $\mathrm{MD}$, for her contribution to the investigation of family B.

\section{References}

1. Perloff JK, De Leon AC, O'Doherty D. The cardiomyopathy of progressive muscular dystrophy. Circulation 1966;33:625648

2. Perloff JK, Roberts WC, De Leon AC, O'Doherty D. The distinctive electrocardiogram of Duchenne's progressive muscular dystrophy. Am J Med 1967;42:179-188

3. Yamamoto $S$, Matsushima $H$, Sotobata $I$, et al. A comparative scudy of thallium-201 single-photon emission computed tomography and electrocardiography in Duchenne and other types of muscular dystrophy. Am J Cardiol 1988;61:836-843

4. Monségu J, Duboc D, Freychet L, et al. L'atteinte cardiaque au cours de certaines maladies musculaires. A propos de 216 observations. Arch Mal Coeur 1993;86:1421-1426

5. De Visser M, De Voogt WG, La Rivière GV. The heart in Becker muscular dystrophy, facioscapulohumeral dystrophy, and Bethlem myopathy. Muscle Nerve 1992;15:591-596

6. Berlit P, Stegaru-Hellring B. The heart in muscular dystrophy: an electrocardiographic and ultrasound study of 20 patients. Eur Arch Psychiatry Clin Neurosci 1991;241:177-180

7. Emery AEH. Emery-Dreifuss muscular dystrophy and other related disorders. Br Med Bull 1989;45:772-787

8. Emery AEH. Emery-Dreifuss syndrome. J Med Genet 1989; 26:637-641

9. Melacini P, Fanin M, Danieli GA, et al. Cardiac involvement in Becker muscular dystrophy. J Am Coll Cardiol 1993;22: 1927-1934

10. Bushby KMD. Limb girdle muscular dystrophy, In: Emery $\mathrm{AEH}$, ed. Diagnostic criteria for neuromuscular disorders. Baarn: De Fontein bv, 1994:25-31

11. Lambert CD, Fairfax AJ. Neurological associations of chronic heart block. I Neurol Neurosurg Psychiatry 1976;39:571-575

12. Welsh JD, Lynn TN, Haase GR. Cardiac findings in 73 patients with muscular dystrophy. Arch Intern Med 1963:112: 97-104

13. Weissleder R, Marfil A, Martinez HR, Rangel-Guerra RA Limb girdle type muscular dystrophy associated with a WolffParkinson-White syndrome. J Neurol Neurosurg Psychiatry 1987;50:500-501

14. Shields RW. Limb girdle syndromes. In: Engel AG, FranziniArmstrong C, eds. Myology. 2nd ed. New York: McGraw-Hill, 1994:1258-1274

15. Piccolo F, Roberds SL, Jeanpierre M, et al. Primary adhalinopathy: a common cause of autosomal recessive muscular dystrophy of variable severity. Nature Genet 1995;10:243-245 
16. Bushby KMD. Workshop report: report on the 12th ENMC sponsored international workshop--the limb girdle muscular dystrophies. Neuromusc Disord 1992;2:3-5

17. Clarke A. Report of ENMC workshop on the limb-girdle muscular dystrophies. J Med Genet 1992;29:753-755

18. Bethlem J, Van Wijngaarden GK. Benign myoparhy with autosomal dominant inheritance. Brain 1976;99:91-100

19. Bacon PA, Smith B. Familial muscular dystrophy of late onset. J Neurol Neurosurg Psychiatry 1971;34:93-97

20. Chutkow JG, Heffner RR, Kramer AA, Edwards JA. Adult onset autosomal dominant muscular dystrophy. Ann Neurol 1986;20:240-248

21. De Coster W, De Reuck J, Thiery E. A late autosomal dominant form of limb girdle muscular dystrophy. Eur Neurol 1974;12:159-172

22. Gilchrist JM, Pericak-Vance M, Silverman L, Roses AD. Clinical and genetic investigations in autosomal dominant limb girdle muscular dystrophy. Neurology 1988;37:5-9

23. Hastings BA, Groothuis DR, Vick NA. Dominantly inherited pseudohypertrophic muscular dystrophy with internalized capillaries. Arch Neurol 1980;37:709-714

24. Marconi G, Pizzi A, Arimondi CG, Vannelli B. Limb girdle muscular dystrophy with autosomal dominant inheritance. Acta Neurol Scand 1991;83:234-238

25. Miller G, Beggs AH, Towfighi J. Early onset autosomal dominant progressive muscular dystrophy presenting in childhood as a Becker phenotype-the importance of dystrophin and molecular generic analysis. Neuromusc Disord 1992;2:121-124

26. Panegyres PK, Mastaglia FL, Kakulas BA. Limb girdle syndromes: clinical, morphological and electrophysiological studies. J Neurol Sci 1990;95:201-218

27. Schneidermann LJ, Sampson WI, Schoene WC, Haydon GB. Genetic studies of a family with two autosomal dominant conditions: muscular dystrophy and Pelger-Huet anomaly. Am J Med 1969;46:380-393

28. Somer H, Laulumaa V, Paljärvi L, et al. Benign muscular dystrophy with autosomal dominant inheritance. Neuromusc Disord 1991;4:267-273

29. Schoeller R, Andresen D, Büttner P, et al. First- or seconddegree atrioventricular block as a risk factor in idiopathic dilated cardiomyopathy. Am J Cardiol 1993;71:720-726

30. Faivre G, Souris D, Gregoire P, et al. Les myocardopathies des affections neuro-musculaires héréditaires. Arch Mal Coeur 1978;71:397-405

31. Ricker K, Koch MC, Lehmann-Horn F, et al. Proximal myotonic myopathy: a new dominant disorder with myotonia, muscle weakness, and cataracts. Neurology 1994;44:14481452

32. Yates JRW. Workshop report: European workshop on EmeryDreifuss muscular dystrophy. Neuromusc Disord 1991;1:393396

33. Rowland LP, Fetell M, Olarte M, et al. Emery-Dreifuss muscular dystrophy. Ann Neurol 1979;5:111-117

34. Mawatari S, Katayama K. Scapuloperoneal muscular atrophy with cardiopathy. An X-linked recessive trait. Arch Neurol 1973;28:55-59

35. Yates JRW, Warner JP, Smith JA, et al. Emery-Dreifuss muscular dystrophy: linkage to markers in distal Xq28. J Med Genet 1993;30:108-111

36. Bione $S$, Maestrini E, Rivella $S$, et al. Identification of a novel $\mathrm{X}$-linked gene responsible for Emery-Dreifuss muscular dystrophy. Nature Genet 1994;8:323-327

37. Nigro V, Bruni P, Ciccodicola A, et al. SSCP detection of novel mutations in patients with Emery-Dreifuss muscular dystrophy: definition of a small C-terminal region required for emerin function. Hum Mol Genet 1995;4:2003-2004
38. Bione S, Small K, Aksmanovic VMA, et al. Identification of new mutations in the Emery-Dreifuss muscular dystrophy gene and evidence for genetic heterogeneity of the disease. Hum Mol Genet 1995;4:1859-1863

39. Chakrabarti A, Pearce JMS. Scapuloperoneal syndrome with cardiomyopathy: report of a family with autosomal dominant inheritance and unusual features. J Neurol Neurosurg Psychiatry 1981;44:1146-1152

40. Miller RG, Layzer RB, Mellenthin MA, et al. Emery-Dreifuss muscular dystrophy with autosomal dominant transmission. Neurology 1985;35:1230-1233

41. Serratrice G, Pouget J. Maladie d'Emery-Dreifuss ou syndrome d'amyotrophie avec rétractions et troubles secondaires de la conduction cardiaque d'hérédité variable. Rev Neurol 1986; $142: 766-770$

42. Merchut MP, Zdonczyk D, Gujrati M. Cardiac transplantation in female Emery-Dreifuss muscular dystrophy. J Neurol 1990; 237:316-319

43. Orstavik KH, Kloster R, Lippestad $\mathrm{C}$, et al. Emery-Dreifuss syndrome in three generations of females, including identical twins. Clin Genet 1990;38:447-451

44. Voit T, Krogmann O, Lenard HG. Emery-Dreifuss muscular dystrophy: disease spectrum and differential diagnosis. Neuropediatrics 1988;19:62-71

45. Witt TN, Garner CG, Pongratz D, Baur X. Autosomal dominant Emery-Dreifuss syndrome: evidence of a neurogenic variant of the disease. Eur Arch Psychiatry Clin Neurosci 1988; 237:230-236

46. Baur X, Witt TN, Pongratz D, et al. Autosomal dominantes Humero-Peroneales Syndrom mit frühzeitigen Kontrakturen und Kardiomyopathie (Emery-Dreifuss-Syndrom), Klin Wochenschr 1987;65:738-745

47. Krendel DA, Jannun DR. A dominantly inherited myopathy with contractures, heart failure, and marked variability of expression. Neurology 1987;37(suppl 1):208-209 (Abstract)

48. Gilchrist JM, Leshner RT. Autosomal dominant humeroperoneal myopathy. Arch Neurol 1986;43:734-735

49. Tanaka K, Yoshimura T, Muratani H, et al. Familial myoparhy with scapulohumeral distribution, rigid spine, cardiopathy and mitochondrial abnormality. J Neurol 1989;236:52-54

50. Galassi $G$, Modena MG, Benassi A, et al. Autosomal-dominant dystrophy with humeroperoneal weakness and cardiopathy: a genetic variant of Emery-Dreifuss muscular dystrophy. Ital J Neurol Sci 1986;7:125-132

51. Hauptmann A, Thannhauser SY. Muscular shortening and dystrophy: a heredofamilial disease. Arch Neurol Psychiatry 1941;46:654-664

52. Emery AEH. Differential diagnosis. In: Emery AEH, ed. Duchenne muscular dystrophy. 2nd ed. Oxford: Oxford Medical Publications, 1993:80-107

53. Fenichel GM, Chul Sul Y, Kilroy AW, Blouin R. An autosomal-dominant dystrophy with humeropelvic distribution and cardiomyopathy. Neurology 1982;32:1399-1401

54. Michaels J, Krol RB, Bach J, et al. Emery-Dreifuss muscular dystrophy (EDMD) with atrial tachycardia and apparent autosomal dominant inheritance. Am J Hum Genet 1991; 49(suppl): 151

55. Takamoto K, Hirose K, Uono M, Nonaka I. A genetic variant of Emery-Dreifuss disease. Muscular dystrophy with humeropelvic distribution, early joint contracture, and permanent atrial paralysis. Arch Neurol 1984;41:1292-1293

56. Graham JM, Rawnsley ES, Nordgren R, Fratkin J. Autosomal dominant limb-girdle muscular dystrophy with progressive cardiomyopathy. Am J Med Genet 1986;25:720-721

57. Fukuhara N, Kumamoto T, Tsubaki T. Rimmed vacuoles. Acta Neuropathol 1980;51:229-235 